Article

\title{
A New Methodological Approach for the Evaluation of Scaling Up a Latent Storage Module for Integration in Heat Pumps
}

\author{
Gabriel Zsembinszki ${ }^{1}\left(\mathbb{D}\right.$, Boniface Dominick Mselle $^{1}{ }^{\oplus}$, David Vérez $^{1}\left(\mathbb{D}\right.$, Emiliano Borri $^{1}{ }^{\circledR}$, Andreas Strehlow $^{2}$, \\ Birgo Nitsch ${ }^{2}$, Andrea Frazzica ${ }^{3}$ (D), Valeria Palomba ${ }^{3, *}$ and Luisa F. Cabeza ${ }^{1}$ (D) \\ 1 GREiA Research Group, Universitat de Lleida, Pere de Cabrera s/n, 25001 Lleida, Spain; \\ gabriel.zsembinszki@udl.cat (G.Z.); boniface.mselle@udl.cat (B.D.M.); david.verez@udl.cat (D.V.); \\ emiliano.borri@udl.cat (E.B.); luisaf.cabeza@udl.cat (L.F.C.) \\ 2 AKG Verwaltungsgesellschaft mbH, Am Hohlen Weg 31, 34369 Hofgeismar, Germany; \\ andreas.strehlow@akg-gruppe.de (A.S.); birgo.nitsch@akg-gruppe.de (B.N.) \\ 3 Istituto di Tecnologie Avanzate per l'Energia “Nicola Giordano", CNR ITAE, 98126 Messina, Italy; \\ andrea.frazzica@itae.cnr.it \\ * Correspondence: valeria.palomba@itae.cnr.it
}

check for updates

Citation: Zsembinszki, G.; Mselle, B.D.; Vérez, D.; Borri, E.; Strehlow, A.; Nitsch, B.; Frazzica, A.; Palomba, V.; Cabeza, L.F. A New Methodological Approach for the Evaluation of Scaling Up a Latent Storage Module for Integration in Heat Pumps. Energies 2021, 14, 7470. https:// doi.org/10.3390/en14227470

Academic Editor: Alessia Arteconi

Received: 14 October 2021

Accepted: 5 November 2021

Published: 9 November 2021

Publisher's Note: MDPI stays neutral with regard to jurisdictional claims in published maps and institutional affiliations.

Copyright: (c) 2021 by the authors. Licensee MDPI, Basel, Switzerland. This article is an open access article distributed under the terms and conditions of the Creative Commons Attribution (CC BY) license (https:/ / creativecommons.org/licenses/by/ $4.0 /)$.

\begin{abstract}
A clear gap was identified in the literature regarding the in-depth evaluation of scaling up thermal energy storage components. To cover such a gap, a new methodological approach was developed and applied to a novel latent thermal energy storage module. The purpose of this paper is to identify some key aspects to be considered when scaling up the module from lab-scale to full-scale using different performance indicators calculated in both charge and discharge. Different normalization methods were applied to allow an appropriate comparison of the results at both scales. As a result of the scaling up, the theoretical energy storage capacity increases by $52 \%$ and $145 \%$, the average charging power increases by $21 \%$ and $94 \%$, while the average discharging power decrease by $16 \%$ but increase by $36 \%$ when mass and volume normalization methods are used, respectively. When normalization by the surface area of heat transfer is used, all of the above performance indicators decrease, especially the average discharging power, which decreases by $49 \%$. Moreover, energy performance in charge and discharge decreases by $17 \%$ and $15 \%$, respectively. However, efficiencies related to charging, discharging, and round-trip processes are practically not affected by the scaling up.
\end{abstract}

Keywords: latent thermal energy storage; phase change material (PCM); performance indicators; scaling up; experimental evaluation; heat pump

\section{Introduction}

The heating and cooling sector in buildings is crucial for the achievement of climate change mitigation targets worldwide [1,2]. Accordingly, the problem of making buildings more efficient has been widely addressed in the literature [3-5]. Hybrid systems, involving the use of multiple generation sources have proved to be able to reach an overall share of renewables higher than $70 \%$ in both residential [6] and office buildings [7]. However, one of the main challenges in the wide deployment of such systems is the proper design methodology. Usually, numerical methods are used, which might include simplified methods based on empirical approaches [8], numerical methods at different scales, such as detailed simulations of a single component [9], and complete studies of the multi-source energy system, usually employing TRNSYS and EnergyPlus $[10,11]$. The outcome of the sizing is often the techno-economic analysis of the overall system [12,13], but its reliability and meaningfulness are highly dependent on data quality for the underlying models [10], especially for thermal systems whose dynamic behavior is more difficult to describe compared to electric ones, thus requiring experimental validation and calibration [14]. If an experimental approach is used, however, the problem is shifting to the proper methodology 
to be used, since full-scale testing is not feasible in several applications and therefore there is a need to operate the design and component selection based on small-scale components intended for laboratory operation. Accordingly, the question of their representativeness arises [15]. Usually, the problem is issued by calibration, through lab-scale experiments, of complex and computationally expensive fluid dynamics models [16]. Such a route, however, is not efficient from an engineering perspective and therefore the evaluation of proper methodological frameworks and parameters for the scaling up from lab-scale to pilot- or full-scale application is needed. The problem of the scale effect of heat transfer in thermal energy storage (TES) is quite new and has not been systematically evaluated so far. In [17], considerations on the scaling up of a molten salt storage facility are reported and the effect of scale on heat losses and auxiliary equipment is discussed. Another attempt to pass from lab-scale to industrial-scale for a TES for a packed-bed system for high temperature waste heat is reported in [18]. The most relevant effect detected in passing from small-scale to the larger system is the amount of stored energy in the insulation, which becomes nonnegligible for heat losses and storage temperature control purposes. In [19], the scaling up of heat transfer surfaces in fluidized beds is discussed, in terms of heat transfer coefficient and correspondence of optimal fluid flow rate and geometric features of the surfaces. The results show that a comparison between different scales is possible when similar operating conditions (Reynolds number, non-dimensional density, and non-dimensional geometrical parameter) are achieved.

Other than the above-reported cases, to the best of the authors' knowledge, there is no systematic investigation of this problem in the literature. The same issue occurs not only with thermal energy storage but also within heat transfer and fluid flow fields [20]. Nonetheless, the scale effect plays a significant role in moving from lab experiments towards system design. For instance, it was demonstrated in [21] for a gas burner that the results from small-scale measurements are only partially applicable for the full-scale system design, in this case due to the radiation effect. Similarly, for the development of a flame in a closed compartment, the scale effect was found to be relevant [22]. The modelling for scaling up/down of the system is based in this case on similarities in the dimensionless group that describe the phenomenon (Reynolds number, Grashof number, Froude number, and Richardson number). In [23], the Six-Sigma methodology was used to go from lab-scale testing to pilot production by converting the outcome of the "Basic Flow Sheet" to a "Detailed Design", with modelling simulations for all the production-critical tasks and their engineering implementation.

From the above-reported literature review it is clear that the in-depth evaluation of the scaling up of thermal systems for energy storage has not been addressed yet. Accordingly, there is a strong need to improve the design process of latent thermal storages, and, particularly, the phase of development from lab-scale to pre-commercial applications. The research here presented is exactly intended to do so: starting from experimental results of a novel latent storage system, which can be embedded within a vapor compression cycle of a heat pump, two sizes are compared and analyzed. Such sizes correspond to the lab-scale and full-scale applications. The main performance indicators (PIs) are calculated and a critical discussion on the methodological approach in the estimation of the component sizing for real-life cases is provided. The final goal of the evaluation is to assess the variations of the PIs as a result of the component scaling up and to give indications on how the scaling up can affect the system operation, thus providing a leap forward in the design phase of latent storages.

\section{Materials and Methods}

\subsection{Description of the Application}

The novel storage system investigated in this study is part of an innovative hybrid electric/thermal storage system developed within the H2020 HYBUILD project [24]. The complete system, described in $[25,26]$, includes a sorption module driven by solar thermal collectors and connected in cascade with a reversible heat pump, in which a latent storage 
system is embedded, acting as an evaporator. A photovoltaic (PV) array is also connected to the heat pump and an electricity storage system through a DC bus for efficient operation (Figure 1). The latent storage system consists of a three-fluid latent heat storage system, which allows for replacing the evaporator of a vapor compression heat pump for embedding a high efficiency latent storage with phase change material (PCM) directly within the vapor compression cycle. The direct integration of PCM into refrigeration systems provides benefits such as reducing the overall number of components of the entire system, reducing system bulkiness, and increasing the useful space when compared to the conventional integration of PCM into such systems.

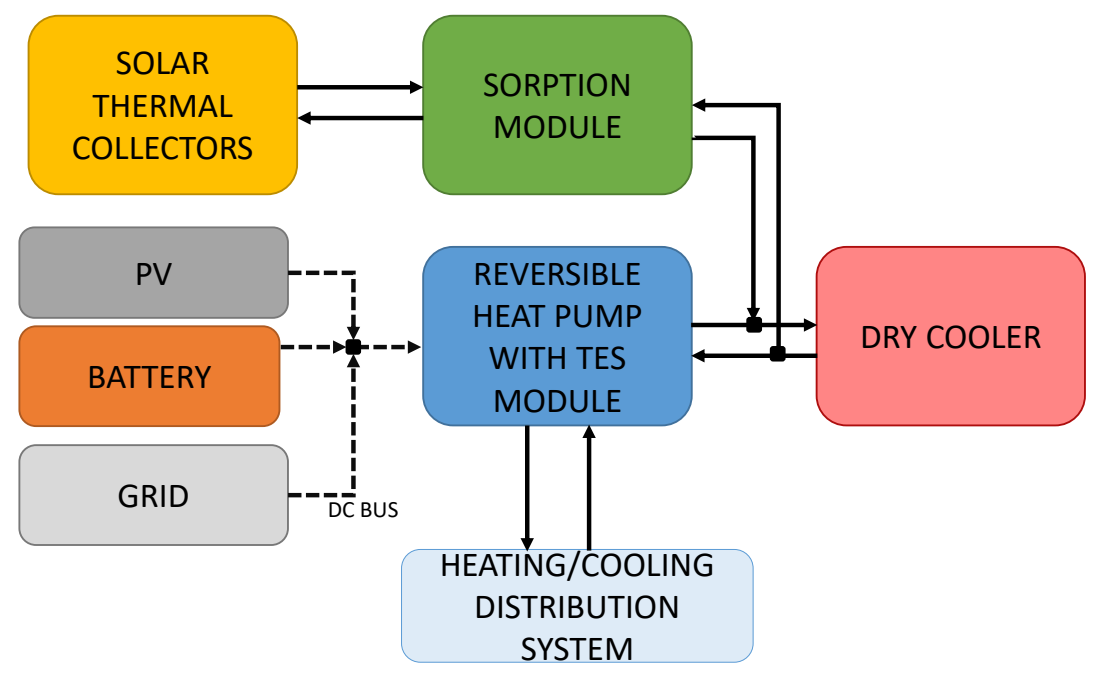

Figure 1. Overall schematic of the innovative system.

The configuration of the innovative system gives high flexibility to the system, which can operate in different modes depending on energy supply availability and energy demand profile. The overall system efficiency can thus be enhanced by the use of PV panels, electric and thermal energy storage, and the cascade coupling between the heat pump and the sorption module, which reduces the temperature lift of the heat pump, therefore increasing its efficiency. Focusing on the latent storage system, it can operate in three different modes: (1) charge via the refrigerant of the heat pump that evaporates inside the storage and cools down the PCM while the cooling distribution system is off, (2) discharge of the cold stored in the PCM to the distribution system while the heat pump is off, and (3) three-fluid heat exchange, when both the heat pump and the distribution system are turned on, thus allowing cold supply from the heat pump to the user through the storage system, which in this case operates as a heat exchanger.

\subsection{Description of the Three-Fluids Latent Storage Module}

In the core of this study, the three-fluid latent storage module is often referred to as a "TES module" or simply "module", for simplicity. As already mentioned at the end of the introduction section, two different modules of different sizes were used to investigate the scaling up from the lab-scale to full-scale application. This subsection describes the details of both lab-scale and full-scale modules that were experimentally tested in different set-ups available at the University of Lleida (Spain) and at CNR-ITAE (Italy) laboratories, respectively.

The two modules shown in Figure 2 were designed to contain PCM layers between the refrigerant and heat transfer fluid (HTF) channels. All channels and PCM layers contain aluminum fins to enhance the heat transfer process. In the PCM layers, dense offset-fins are used, with the ability to hold a large amount of PCM and with high mechanical stability able to withstand stresses from the volume changes of the PCM during phase change. Channel distribution is shown in Figure 2c,f for lab-scale and full-scale modules, respectively. 


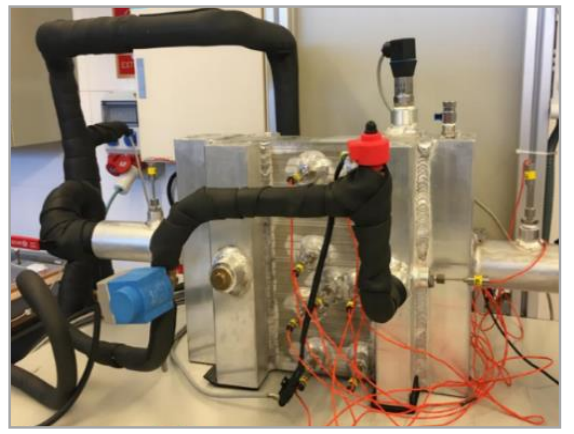

(a)

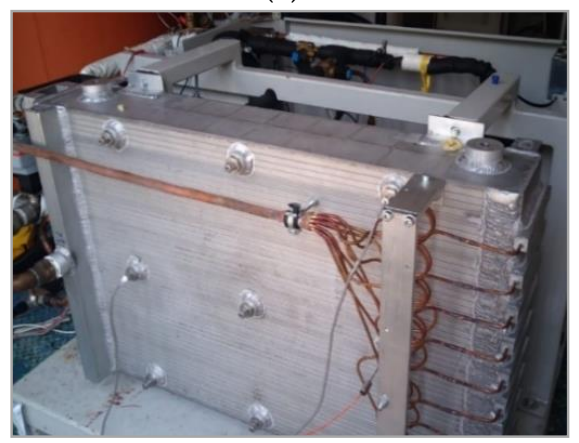

(d)

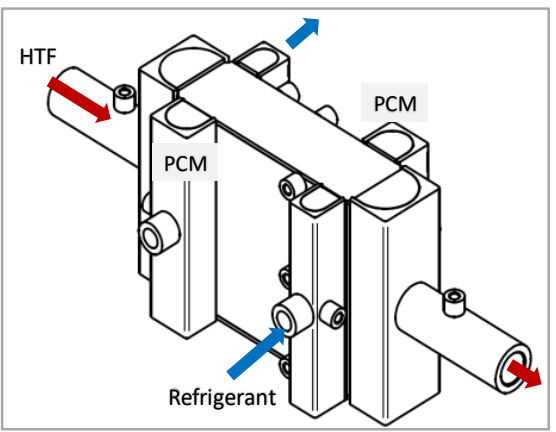

(b)

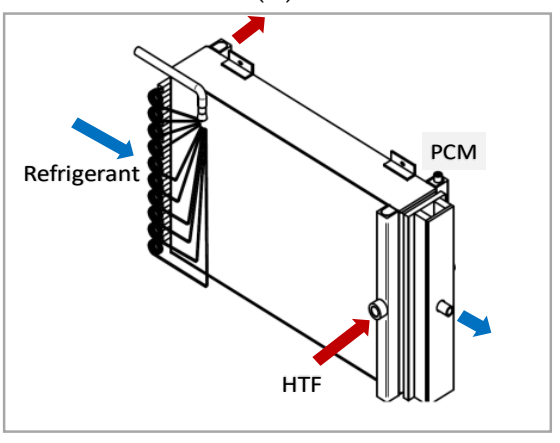

(e)

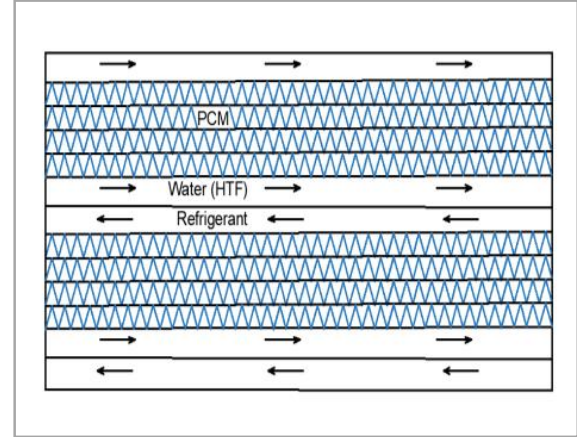

(c)

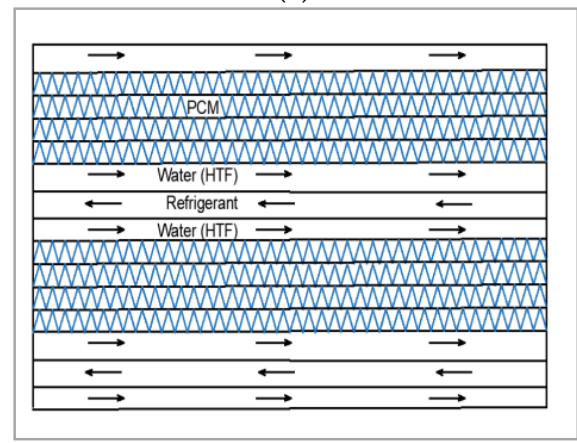

(f)

Figure 2. Details of the two storage modules: (a) photo of the lab-scale module before insulation, (b) lab-scale module flow direction, (c) lab-scale module arrangement of the channels, (d) photo of the full-scale module before insulation, (e) full-scale module flow direction, and (f) full-scale module arrangement of the channels.

Both modules were insulated with a $120 \mathrm{~mm}$-thick layer of mineral wool. The overall mass and volume of the storage system is the sum of all materials comprised in the module and the insulation material. The details on sizing, number of channels, and amount of material in each of the two modules are given in Table 1. The size of the full-scale module corresponds to the real-scale component implemented in the system installed at the demonstration site.

Table 1. Sizing and design details of the two TES modules.

\begin{tabular}{ccc}
\hline Variable & Lab-Scale & Full-Scale \\
\hline Number of PCM layers (-) & 24 & 44 \\
Number of refrigerant channels $(-)$ & 5 & 10 \\
Number of HTF channels $(-)$ & 7 & 22 \\
Module height $(\mathrm{m})$ & 0.310 & 0.637 \\
Module length $(\mathrm{m})$ & 0.420 & 1.100 \\
Module width $(\mathrm{m})$ & 0.094 & 0.160 \\
Mass of PCM $(\mathrm{kg})$ & 3.7 & 40.0 \\
Mass of aluminum $(\mathrm{kg})$ & 20.4 & 148.0 \\
Mass of HTF inside the module $(\mathrm{kg})$ & 3.3 & 5.0 \\
Total mass without insulation $(\mathrm{kg})$ & 27.4 & 193.0 \\
Mass of insulation $(\mathrm{kg})$ & 6.9 & 23.0 \\
Total mass including insulation $(\mathrm{kg})$ & 34.3 & 216.0 \\
Volume without insulation $\left(\mathrm{m}^{3}\right)$ & 0.0153 & 0.1166 \\
Volume including insulation $\left(\mathrm{m}^{3}\right)$ & 0.1210 & 0.4701 \\
Heat transfer area of PCM layers $\left(\mathrm{m}^{2}\right)$ & 0.34 & 3.52 \\
\hline
\end{tabular}

The main difference in the channel arrangement between the two modules is as follows: in the lab-scale module, each refrigerant channel is close to an HTF channel on one side and 4 PCM channels on the other, whereas in the full-scale module both sides of the refrigerant channel are in contact with the HTF channels. In this way (i.e., by increasing 
the number of HTF channels for each refrigerant one), it was possible to comply with the required flow rates for the correct operation of the heat pump.

According to the values shown in Table 1, the material that has the highest share in terms of mass in the lab-scale module is the aluminum $(60 \%)$, followed by the insulation $(20 \%)$, the PCM $(11 \%)$, and the HTF $(10 \%)$. In the full-scale module, the aluminum is also the material with the highest share $(69 \%)$, followed by the PCM $(19 \%)$, the insulation (10\%), and the HTF $(2 \%)$. In terms of volume, the situation is very different, the insulation being the material with the highest share in both modules ( $87 \%$ in the lab-scale and $75 \%$ in the full-scale). Another useful relation that can be obtained from Table 1 is the mass ratio of aluminum to PCM, which is equal to 5.5 in the lab-scale and 3.7 in the full-scale system.

\subsection{Description of the Experimental Set-Ups}

\subsubsection{Lab-Scale Testing Set-Up}

The experimental facility used for testing the lab-scale storage system was built at the laboratory of GREiA research group at the University of Lleida, in Spain (Figure 3). The test-rig consists of a refrigeration system, in which the storage system was installed as an evaporator, and a thermostatic bath working with water-glycol as the HTF, making two independent loops. The refrigerant loop that supplies cold to the TES module consists of a condensing unit (Zanotti model GCU2030ED01B) able to work at different operation powers, working with R449A refrigerant. The unit is made of a hermetic scroll compressor (CU E scroll digital), an electronic expansion valve, and an air-cooled condenser. According to the manufacturer, the condensing unit has a maximum cooling power of $4.956 \mathrm{~kW}$ with a coefficient of performance (COP) of 2.12 when operating at an evaporation temperature of $-10{ }^{\circ} \mathrm{C}$ and ambient at $32{ }^{\circ} \mathrm{C}$. However, the actual cooling power of the condensing unit can be varied by adjusting the compressor power rate down to $15 \%$ of its maximum. The HTF loop was built to ensure a stable inlet temperature into the module by incorporating two immersion electric heaters (OVAN TH100E-2kW and JP SELECTA-1kW) and two immersion chillers (JP SELECTA FRIGEDOR-285W) into a water bath. Moreover, the loop also contains a pump for HTF circulation and an advanced flow meter (Badger Meter Primo) with an accuracy of $\pm 0.25 \%$. For data acquisition, 13 temperature sensors (Pt-100 class B, IEC 60751 standard type) with an accuracy of $\pm 0.3^{\circ} \mathrm{C}$ were used, nine of them to measure the temperature evolution in the PCM, two of them at the inlet and outlet of the refrigerant loop, respectively, and the other two at the inlet and outlet of the HTF loop, respectively.

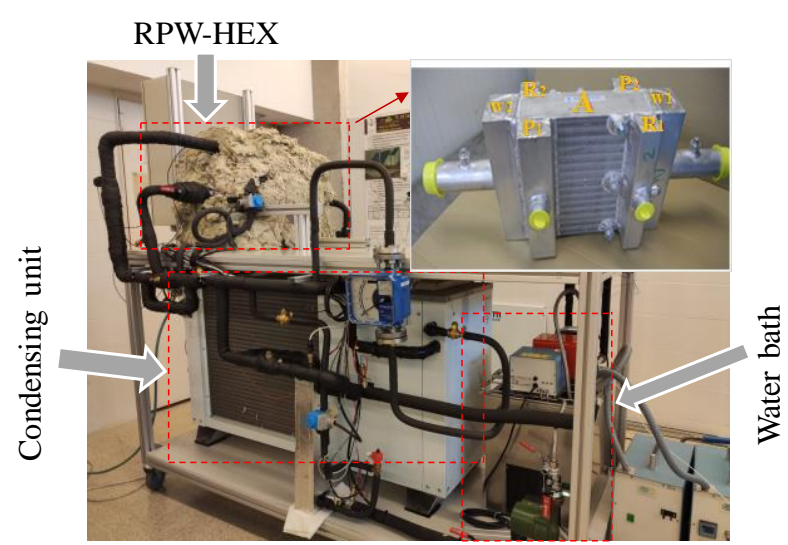

(a)

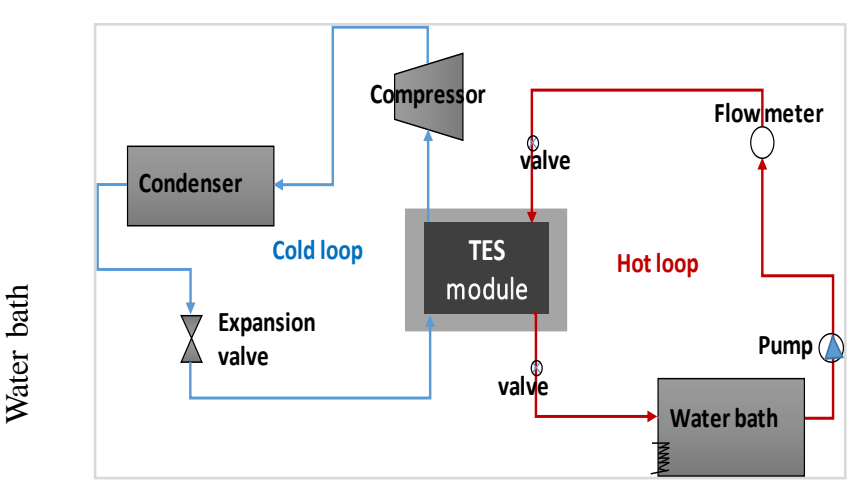

(b)

Figure 3. Lab-scale experimental set-up: (a) photo of the test-rig and (b) schematic diagram.

\subsubsection{Full-Scale Testing Set-Up}

The full-scale TES module was tested at CNR-ITAE using the testing rig for hybrid thermal systems described in [27]. It mainly consists of three thermal storages which are 
able to supply different temperature levels. A $0.5 \mathrm{~m}^{3}$ storage was connected to an electric heater, to simulate a thermal heat source, a $0.3 \mathrm{~m}^{3}$ storage was connected to a thermal chiller, simulating ambient heat sink, and a $0.75 \mathrm{~m}^{3}$ storage was connected to a thermal chiller equipped with immersed resistances that simulated the user sink. All circuits were equipped with variable speed drivers and magnetic flow meters (Bronkhorst MVM-250 PA, $\pm 1.5 \%$ accuracy) and type $\mathrm{T}$ thermocouples. For the present tests, however, temperatures in the HTF circuits, refrigerant circuit, and in two locations of the PCM storage (middle section, $100 \mathrm{~mm}$ from the top and $100 \mathrm{~mm}$ from the bottom) were measured by means of Pt-100 temperature sensors (UTECO, $\pm 0.1{ }^{\circ} \mathrm{C}$ accuracy). In addition, the pressure of the refrigerant in the condenser and at inlet and outlet of the evaporator was measured using piezoresistive pressure meters (ALCO Controls, $\pm 1 \%$ F.S. accuracy). cDAQ and cRIO boards by National Instruments were used for data acquisition and control.

The heat pump integrated with the storage module uses R410a refrigerant and has a nominal power of $14 \mathrm{~kW}$. The compressor is equipped with an air-cooled inverter drive (VACON INU series, model NXI0095) that allows DC-powered operation in the range of 465-800 VDC, varying also the driving frequency of the compressor.

Some pictures of the installed heat pump with integrated TES module are shown in Figure 4 .

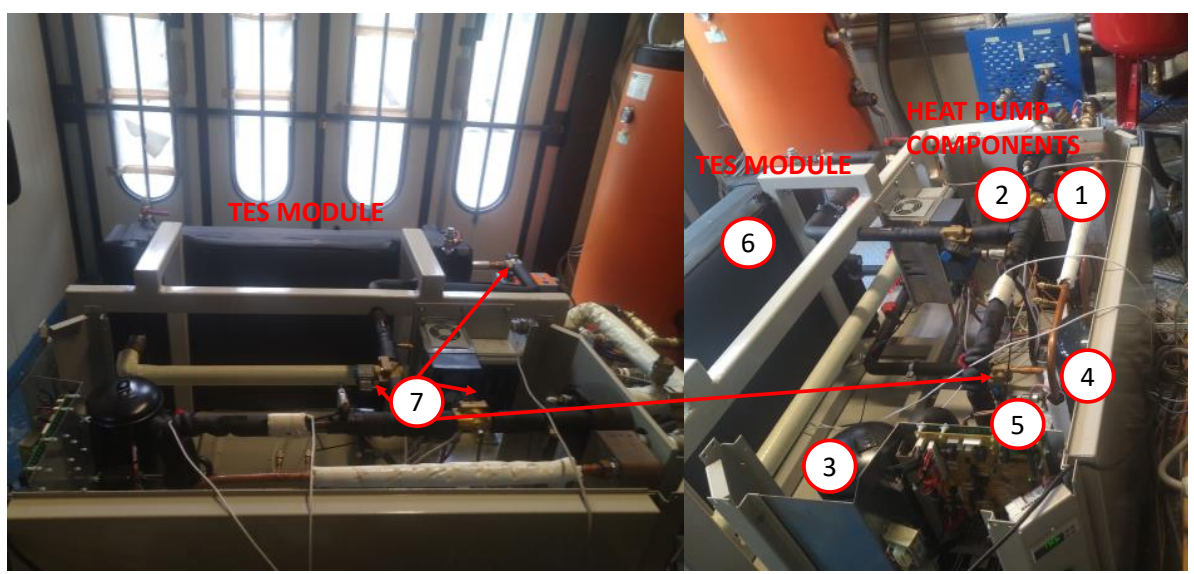

Figure 4. Installed heat pump with integrated TES module. The main components are highlighted: (1) condenser, (2) standard evaporator, (3) compressor, (4) liquid receiver, (5) TEX valve, (6) TES module, and (7) solenoid valves.

\subsection{Materials Properties}

Both modules were filled with an organic PCM, the commercial RT4 from Rubitherm [28], with a phase change temperature around $5{ }^{\circ} \mathrm{C}$. The relation in Equation (1), derived in a previous study [29], was applied to obtain the enthalpy of the PCM as a function of temperature:

$$
h_{P C M}(T)=\left\{\begin{array}{c}
152.49+2.64 \cdot(-4-T)\left[\mathrm{kJ} \cdot \mathrm{kg}^{-1}\right], \text { if } T<-4{ }^{\circ} \mathrm{C} \\
-0.1139 \cdot T^{3}-1.3116 \cdot T^{2}-8.5545 \cdot T+131.97\left[\mathrm{~kJ} \cdot \mathrm{kg}^{-1}\right], \text { if }-4{ }^{\circ} \mathrm{C} \leq T<6{ }^{\circ} \mathrm{C} \\
-0.0985 \cdot T^{3}+2.8732 \cdot T^{2}-28.629 \cdot T+99.839\left[\mathrm{~kJ} \cdot \mathrm{kg}^{-1}\right], \text { if } 6{ }^{\circ} \mathrm{C} \leq T \leq 12{ }^{\circ} \mathrm{C} \\
-2.38 \cdot(T-12)\left[\mathrm{kJ} \cdot \mathrm{kg}^{-1}\right], \text { if } T>12{ }^{\circ} \mathrm{C}
\end{array}\right.
$$

where $h_{P C M}(T)$ is the specific enthalpy of the PCM at temperature $T$.

Equation (1) was obtained by data fitting from the thermograms obtained through Differential Scanning Calorimetry analysis. $\mathrm{R}^{2}>0.98$ was calculated for the fitting, thus proving that the derived equation can be used to accurately calculate the energy stored in the PCM. 
As mentioned in the previous section, both modules were connected to a refrigeration system and an HTF loop, which were used as cold supply and sink for the charging and the discharging processes, respectively. The HTF loops contained a mixture of water-glycol at $30 \%$ glycol concentration in the lab-scale and at $10 \%$ in the full-scale set-up, at a temperature above the PCM melting point. The thermo-physical properties of the HTF used in the lab-scale set-up according to the manufacturer [23] are as follows: freezing temperature at $-18{ }^{\circ} \mathrm{C}$, average density of $1050.45 \mathrm{~kg} \cdot \mathrm{m}^{-3}$, average specific heat of $3601.5 \mathrm{~J} \cdot \mathrm{kg}^{-1} \cdot \mathrm{K}^{-1}$, and average thermal conductivity of $0.4275 \mathrm{~W} \cdot \mathrm{m}^{-1} \cdot \mathrm{K}^{-1}$ in the temperature range between $12{ }^{\circ} \mathrm{C}$ and $-4{ }^{\circ} \mathrm{C}$. The thermo-physical properties of the HTF used in the full-scale setup are freezing temperature at $-3.4^{\circ} \mathrm{C}$, average density of $1018 \mathrm{~kg} \cdot \mathrm{m}^{-3}$, and average specific heat of $4071 \mathrm{~J} \cdot \mathrm{kg}^{-1} \cdot \mathrm{K}^{-1}$ in the temperature range between $12^{\circ} \mathrm{C}$ and $-4{ }^{\circ} \mathrm{C}$. For the aluminum, the value of $900 \mathrm{~J} \cdot \mathrm{kg}^{-1} \cdot \mathrm{K}^{-1}$ was used for the specific heat capacity [30]. Moreover, both modules were insulated with $120 \mathrm{~mm}$ of mineral wool, with thermal conductivity $k=0.04 \mathrm{~W} \cdot \mathrm{m}^{-1} \cdot \mathrm{K}^{-1}$ and density of $60 \mathrm{~kg} \cdot \mathrm{m}^{-3}$ [31] and $65 \mathrm{~kg} \cdot \mathrm{m}^{-3}$ [32] for the full-scale and the lab-scale modules, respectively.

\subsection{Experimental Methodology}

Although there are three possible operation modes of the TES module, i.e., charge, discharge, and three-fluid heat exchange mode, only charge and discharge modes were used in the analysis of the scaling up of the storage modules. The charging process started with the PCM in liquid phase and it was cooled down until most of the PCM solidified. A cooling fraction of $20 \%$ was used in the lab-scale set-up, while a constant compressor frequency of $25 \mathrm{~Hz}$ was used in the full-scale set-up. For the present design, the variation of the capacity of the heat pump was not considered. Indeed, for both lab-scale and full-scale prototypes, the results under optimal operating conditions are considered and, since the scope of the investigation is to compare the effect of scaling up of the system, the variation of the capacity of the heat pump is not relevant nor significantly affects the outcomes of the analysis. A predictive mathematical model for the system, including the effect of the variation of the layout and heat pump capacity on system performance, are instead presented in [33]. The discharging process started with most of the PCM in a solid state and it was heated up by the HTF that entered the storage module at constant temperature of around $12{ }^{\circ} \mathrm{C}$. The discharging process finished when most of the PCM was in a liquid state. A constant flow rate of $100 \mathrm{~L} \cdot \mathrm{h}^{-1}$ was used in the lab-scale set-up, while a constant flow rate of $900 \mathrm{~L} \cdot \mathrm{h}^{-1}$ was used in the full-scale set-up. A summary of the testing conditions in both set-ups is given in Table 2 .

Table 2. Summary of testing conditions in both set-ups.

\begin{tabular}{ccc}
\hline Process & Lab-Scale & Full-Scale \\
\hline Charge & Cooling fraction $(\%)$ & Compressor frequency $(\mathrm{Hz})$ \\
& 20 & 25 \\
Discharge & HTF flow rate $\left(\mathrm{L} \cdot \mathrm{h}^{-1}\right)$ & HTF flow rate $\left(\mathrm{L} \cdot \mathrm{h}^{-1}\right)$ \\
& 100 & 900 \\
\hline
\end{tabular}

The values of the HTF flow rates used in both lab-scale and full-scale set-ups correspond to laminar flow in both cases, which ensures that the discharging processes are comparable.

\subsection{Theoretical Evaluation}

Estimations of the energy supplied to the TES modules during charge and recovered from the modules during discharge are needed to assess the performance of the modules in both charge and discharge modes. In practical application, energy losses are unavoidable during both processes and should be considered in the evaluation of modules performance.

As shown in Figure 5, the net energy stored in the TES module at the end of the charge $\left(E_{n e t, T E S, c h}\right)$ is always lower than the total energy supplied by the refrigeration system $\left(E_{c h}\right)$, 
and the energy recovered from the module $\left(E_{n e t, T E S, \text { dis }}\right)$ is always lower than the energy variation of the module during the discharge $\left(E_{d i s}\right)$, which is equal to the net energy stored in the module at the end of a previous charge (i.e., $\left.E_{d i s}=E_{n e t, T E S, c h}\right)$. The net energy available in the module after the charge (i.e., at the beginning of the discharge) is also referred to as the energy storage capacity $\left(E S C_{T E S}\right)$ of the TES module.

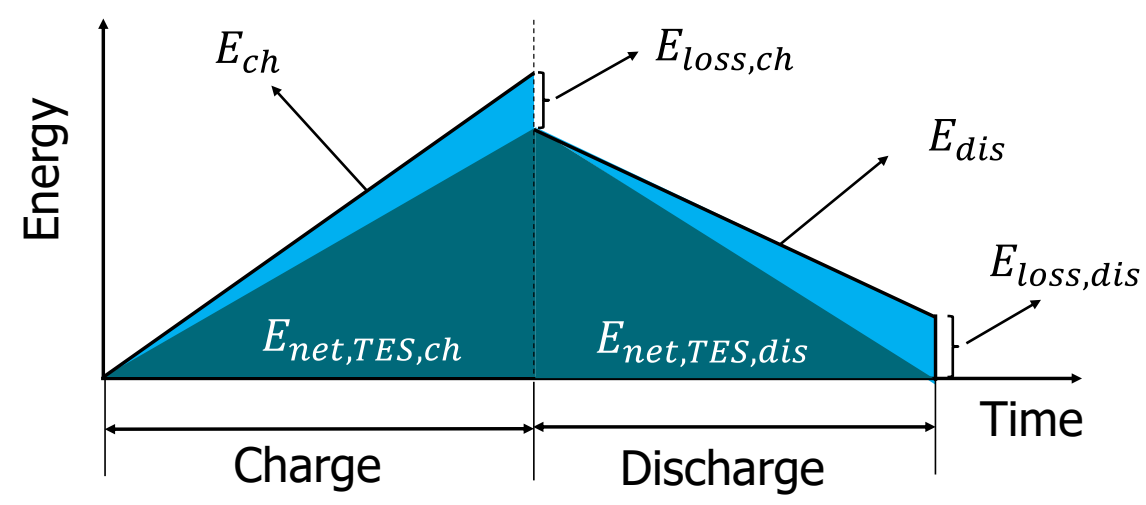

Figure 5. Energy storage flow chart.

The overall cold energy supplied by the refrigeration system $\left(E_{c h}\right)$ was evaluated as shown in Equation (2) [34,35].

$$
E_{c h}=E_{n e t, T E S, c h}+E_{l o s s, c h}
$$

where $E_{n e t, T E S, c h}$ is the net energy stored in the module during the charging process and $E_{l o s s, c h}$ are heat losses during this process. $E_{n e t, T E S, c h}$ was calculated as the sum of the energy contained in the different materials and depends on the temperature of each volume element, as shown in Equation (3).

$$
E_{n e t, T E S, c h}=\sum_{i=1}^{n}\left[m_{P C M, i} \cdot\left(h_{P C M}\left(T_{i}\right)-h_{P C M}\left(T_{i, 0}\right)\right)+\left(m_{A l, i} \cdot C p_{A l}+m_{H T F, i} \cdot C p_{H T F}\right) \cdot\left(T_{i, 0}-T_{i}\right)\right]
$$

where the sub-index $i$ indicates that the variable refers to the volume element $i, n$ is the number of volume elements considered in each TES module (equal to the number of temperature sensors installed, i.e., $n=9$ in the lab-scale and $n=8$ in the full-scale), $m_{P C M, i}, m_{A l, i}$, and $m_{H T F, i}$ are the masses of PCM, aluminum (container material), and HTF contained in volume element $i$, respectively, $C p_{A l}$ and $C p_{H T F}$ are the specific heat capacities of aluminum and HTF, respectively, $T_{i}$ is the temperature of volume element $i$ at any time instant during the charge, and $T_{i, 0}$ is the initial temperature of volume element $i$.

Heat losses from the modules during the charge were estimated according to Equation (4).

$$
E_{\text {loss }, c h}=\sum_{t=0}^{t_{c h}}\left[U A_{\text {loss }} \cdot\left(T_{a m b}-T_{a v}\right)_{t}\right] \cdot \Delta t
$$

where $U A_{\text {loss }}$ is the overall heat transfer coefficient for heat losses from the module to the ambient air (estimated as $0.98 \mathrm{~W} \cdot \mathrm{K}^{-1}$ and $7.8 \mathrm{~W} \cdot \mathrm{K}^{-1}$ for the lab-scale and full-scale modules, respectively), $T_{a m b}$ is the ambient air temperature, $T_{a v}$ is the average temperature of the module (calculated as the arithmetic average of the values measured by each temperature sensor), $t_{c h}$ is the duration of the charging process, $\Delta t$ is the time interval between temperature measurements, and $t$ refers to a specific time instant.

The average charging power $\left(\overline{\dot{E}}_{c h}\right)$ was evaluated as in Equation (5).

$$
\overline{\dot{E}}_{c h}=\frac{E_{n e t, T E S, c h}}{t_{c h}}
$$


The total energy variation of the TES module $\left(E_{\text {dis }}\right)$ during the discharging process was evaluated as shown in Equation (6).

$$
E_{d i s}=E_{n e t, T E S, d i s}+E_{l o s s, d i s}
$$

where $E_{n e t, T E S, d i s}$ is the net energy recovered from the module through the HTF loop and $E_{l o s s, d i s}$ are heat losses during the discharge. $E_{n e t, T E S, \text { dis }}$ was calculated using an energy balance in the HTF between the inlet and the outlet of the module, as shown in Equation (7).

$$
E_{\text {net }, T E S, d i s}=\sum_{t=0}^{t_{\text {dis }}}\left[\dot{V}_{H T F} \cdot \rho_{H T F} \cdot C p_{H T F} \cdot\left(T_{H T F, \text { in }}-T_{H T F, \text { out }}\right)\right]_{t} \cdot \Delta t
$$

where $\dot{V}_{H T F}$ is the volume flow rate of the HTF, $\rho_{H T F}$ is the density of the HTF, $T_{H T F, i n}$ and $T_{H T F, \text { out }}$ are the temperatures of the HTF at the inlet and outlet of the module, respectively, and $t_{d i s}$ is the duration of the discharging process.

Similar to the charging process, heat losses from the module during the discharge were estimated according to Equation (8).

$$
E_{\text {loss }, \text { dis }}=\sum_{t=0}^{t_{d i s}}\left[U A_{\text {loss }} \cdot\left(T_{a m b}-T_{a v}\right)_{t}\right] \cdot \Delta t
$$

The average discharging power $\left(\overline{\dot{E}}_{d i s}\right)$ was evaluated as in Equation (9).

$$
\overline{\dot{E}}_{\text {disc }}=\frac{E_{n e t, T E S, \text { dis }}}{t_{\text {dis }}}
$$

\subsection{Definition of the Performance Indicators (PIs) Considered}

Different PIs were selected for the comparison of the two TES modules. Because of the difference in size between the two modules analyzed in this study, some of the PIs had to be normalized to allow for a proper and meaningful comparison of the two modules. Given the dual nature of the modules, which can act both as a TES device and as a heat exchanger, different normalization methods were used: by mass $\left(m_{T E S}\right)$, by volume $\left(V_{T E S}\right)$, and by heat transfer surface area $\left(A_{H E X}\right)$. The first two normalization methods are typically used for TES devices, while normalization by heat transfer surface area is commonly used for heat exchangers.

The first PIs considered in this study were the following structure PIs: the PCM mass ratio $\left(m_{P C M @ m}\right)$, PCM volume ratio $\left(V_{P C M @ V}.\right)$, also known as packing factor, and PCM volume per heat transfer surface area $\left(V_{P C M @ A}\right)$, which were evaluated using Equations (10)-(12), respectively.

$$
\begin{array}{cc}
m_{P C M @ m}=\frac{m_{P C M}}{m_{T E S}} & {\left[\mathrm{~kg} \cdot \mathrm{kg}^{-1}\right]} \\
V_{P C M @ V}=\frac{V_{P C M}}{V_{T E S}} & {\left[\mathrm{~m}^{3} \cdot \mathrm{m}^{-3}\right]} \\
V_{P C M @ A}=\frac{V_{P C M}}{A_{H E X}} & {\left[\mathrm{~m}^{3} \cdot \mathrm{m}^{-2}\right]}
\end{array}
$$

where $m_{P C M}$ and $V_{P C M}$ are the mass and volume of the PCM, respectively, and $A_{H E X}$ is the surface area for heat transfer between PCM and the heat transfer fluids.

Next, the theoretical energy storage capacity $\left(\mathrm{ESC}_{T E S}\right)$ was considered, which was calculated from Equation (3) as the increase in the energy stored in the TES module $\left(\triangle E_{n e t, T E S, c h}\right)$ when its average temperature decreased from $9^{\circ} \mathrm{C}$ to $-2{ }^{\circ} \mathrm{C}$, and assuming a uniform temperature distribution inside the module. The energy storage capacity was normalized by mass $\left(E S C_{T E S @ m}\right)$, by volume $\left(E S C_{T E S @ V}\right)$, and by heat transfer surface 
area $\left(E S C_{T E S @ A}\right)$ as shown in Equations (13)-(15), respectively. This PI is not related to the dynamic of the system in charge or discharge modes, rather it is an indicator of the maximum energy density that can be reached in the ideal case.

$$
\begin{aligned}
E S C_{T E S @ m}=\frac{E S C_{T E S}}{m_{T E S}} & {\left[\mathrm{~kJ} \cdot \mathrm{kg}^{-1}\right] } \\
E S C_{T E S @ V}=\frac{E S C_{T E S}}{V_{T E S}} & {\left[\mathrm{MJ} \cdot \mathrm{m}^{-3}\right] } \\
E S C_{T E S @ A}=\frac{E S C_{T E S}}{A_{H E X}} & {\left[\mathrm{MJ} \cdot \mathrm{m}^{-2}\right] }
\end{aligned}
$$

The following PIs calculated in this study were defined based on the average power of both charging and discharging processes. The average charging power normalized by mass $\left(P_{c h @ m}\right)$, by volume $\left(P_{c h @ V}\right)$, and by heat transfer surface area $\left(P_{c h @ A}\right)$ was evaluated according to Equations (16)-(18), respectively.

$$
\begin{aligned}
& P_{c h @ m}=\frac{\overline{\dot{E}}_{c h}}{m_{T E S}} \quad\left[\mathrm{~W} \cdot \mathrm{kg}^{-1}\right] \\
& P_{c h @ V}=\frac{\overline{\dot{E}}_{c h}}{V_{T E S}} \quad\left[\mathrm{~kW} \cdot \mathrm{m}^{-3}\right] \\
& P_{c h @ A}=\frac{\overline{\dot{E}}_{c h}}{A_{H E X}} \quad\left[\mathrm{~kW} \cdot \mathrm{m}^{-2}\right]
\end{aligned}
$$

where $\overline{\dot{E}}_{c h}$ is the average charging power as defined in Equation (5).

Similarly, the average discharging power normalized by mass $\left(P_{d i s @ m}\right)$, by volume $\left(P_{d i s @ V}\right)$, and by heat transfer surface area $\left(P_{d i s @ A}\right)$ was evaluated according to Equations (19)-(21), respectively.

$$
\begin{aligned}
P_{d i s @ m}=\frac{\overline{\dot{E}}_{d i s}}{m_{T E S}} & {\left[\mathrm{~W} \cdot \mathrm{kg}^{-1}\right] } \\
P_{d i s @ V}=\frac{\overline{\dot{E}}_{d i s}}{V_{T E S}} & {\left[\mathrm{~kW} \cdot \mathrm{m}^{-3}\right] } \\
P_{d i s @ A}=\frac{\overline{\dot{E}}_{d i s}}{A_{H E X}} & {\left[\mathrm{~kW} \cdot \mathrm{m}^{-2}\right] }
\end{aligned}
$$

where $\overline{\dot{E}}_{\text {dis }}$ is the average discharging power as defined in Equation (9).

To investigate the actual behavior of the TES modules in both charge and discharge, the energy performance of the module was also considered. For the charging process, the energy performance $\left(\varepsilon_{c h}\right)$ was evaluated according to Equation (22).

$$
\varepsilon_{c h}=\frac{E_{n e t, T E S, c h}}{\operatorname{ESC}_{T E S}} \quad[-]
$$

where $E_{n e t, T E S, c h}$ is the net energy stored in the module during the charging process as defined in Equation (3).

For the discharging process, the energy performance $\left(\varepsilon_{c h}\right)$ was evaluated according to Equation (23).

$$
\varepsilon_{\text {dis }}=\frac{E_{n e t, T E S, \text { dis }}}{\mathrm{ESC}_{T E S}}
$$

where $E_{n e t, T E S, \text { dis }}$ is the net energy recovered from the module during the discharging process as defined in Equation (7). 
Other PIs considered were the charging efficiency $\left(\eta_{c h}\right)$, the discharging efficiency $\left(\eta_{\text {dis }}\right)$, and the overall efficiency $\left(\eta_{\text {overall }}\right)$, which were defined as shown in Equations (24)(26), respectively.

$$
\begin{gathered}
\eta_{c h}=\frac{E_{n e t, T E S, c h}}{E_{c h}} \quad[-] \\
\eta_{d i s}=\frac{E_{n e t, T E S, \text { dis }}}{E_{\text {dis }}} \quad[-] \\
\eta_{\text {overall }}=\eta_{c h} \cdot \eta_{\text {dis }}=\frac{E_{n e t, T E S, \text { dis }}}{E_{c h}} \quad[-]
\end{gathered}
$$

where $E_{c h}$ and $E_{d i s}$ were defined in Equations (2) and (6), respectively.

\section{Results}

\subsection{Test Results}

Figure 6 shows the temperature evolution and the net energy charged into the TES modules during the charging process, for both lab-scale and full-scale modules. All PIs were evaluated for both modules in the same temperature range corresponding to an average module temperature between $9{ }^{\circ} \mathrm{C}$ and $-2{ }^{\circ} \mathrm{C}$, for which most of the PCM underwent a complete phase change from liquid to solid states. However, the temperature distribution in both cases was not uniform, and a temperature difference of more than $10 \mathrm{~K}$ was observed between the top and bottom parts of the modules. Due to this temperature gradient, even though the average temperature was well below the PCM solidification temperature, in some parts at the top region of the modules the PCM was still undergoing phase change or was even in its liquid phase at the end of the charging process.

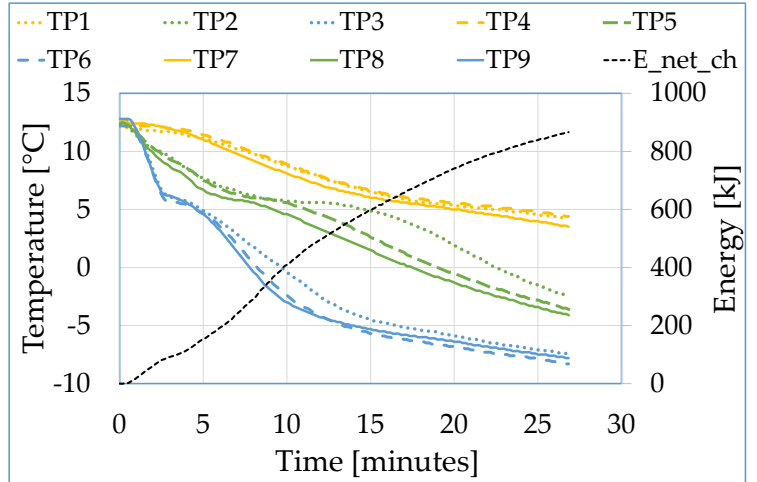

(a)

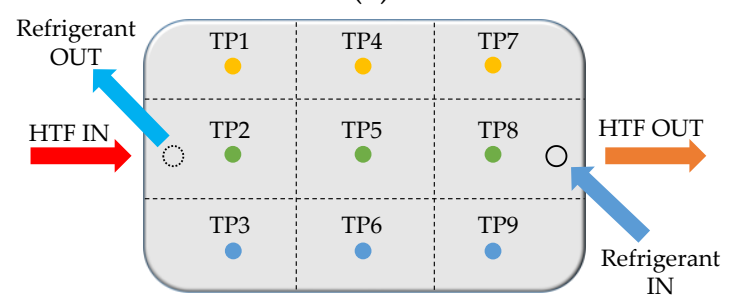

(c)

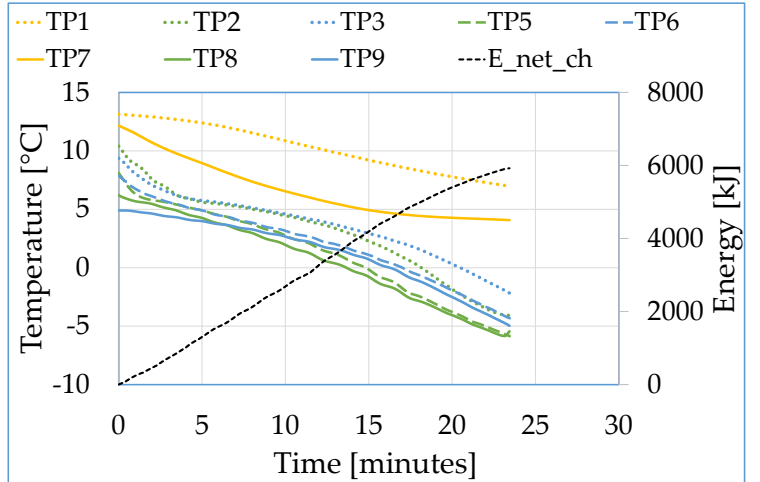

(b)

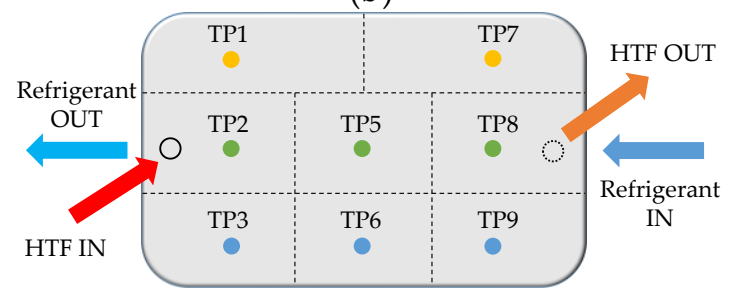

(d)

Figure 6. Results for the charging process: (a) lab-scale temperature evolution and net energy charged, (b) full-scale temperature evolution and net energy charged, (c) location of lab-scale temperature sensors, and (d) location of full-scale temperature sensors.

In terms of energy storage, Figure $6 \mathrm{a}, \mathrm{b}$ also show the net energy stored during the charging process into the lab-scale and full-scale modules, respectively. In both cases, the curves indicate the relative increase in the energy stored in the module with respect to the energy at the initial time $(t=0)$. The average temperature decreased from $9^{\circ} \mathrm{C}$ to $-2{ }^{\circ} \mathrm{C}$ in 
$22.5 \mathrm{~min}$ and $23.4 \mathrm{~min}$ for the lab-scale and full-scale modules, respectively. During these time intervals, $753 \mathrm{~kJ}$ were charged into the lab-scale module and $5922 \mathrm{~kJ}$ into the full-scale module, which are equivalent to an average charging power $\left(\overline{\dot{E}}_{c h}\right)$ of $0.56 \mathrm{~kW}$ and $4.21 \mathrm{~kW}$ for the lab-scale and full-scale TES modules, respectively.

Figure 7 shows the temperature evolution and energy recovered during the discharging process for both lab-scale and full-scale modules. Similarly to the charging process, the discharging process was stopped when most of the PCM had undergone phase change, in this case from a solid to liquid state. For consistency, the same temperature range as for the charging process was used for the average temperature, i.e., between $-2{ }^{\circ} \mathrm{C}$ and $9{ }^{\circ} \mathrm{C}$. Here also, a temperature gradient between the bottom and top parts of the TES module was observed in both modules, meaning that the phase change occurred primarily in the direction from top to bottom, rather than from HTF inlet to HTF outlet. This can be clearly seen in the full-scale module (Figure 7b), in which case the PCM located at the top of the module melted after less than $2 \mathrm{~min}$, while the PCM located at the bottom of the module started to melt after about $30 \mathrm{~min}$ from the beginning of the process, and most of the PCM at that part was still in solid state at the end of the process.

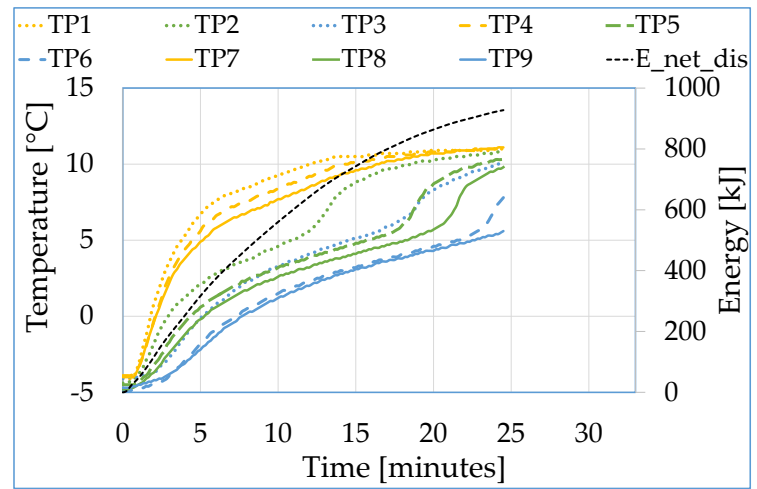

(a)

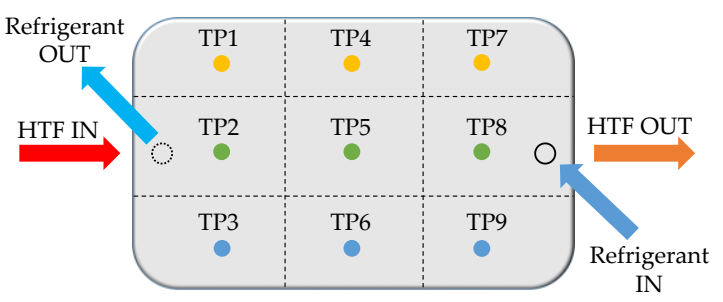

(c)

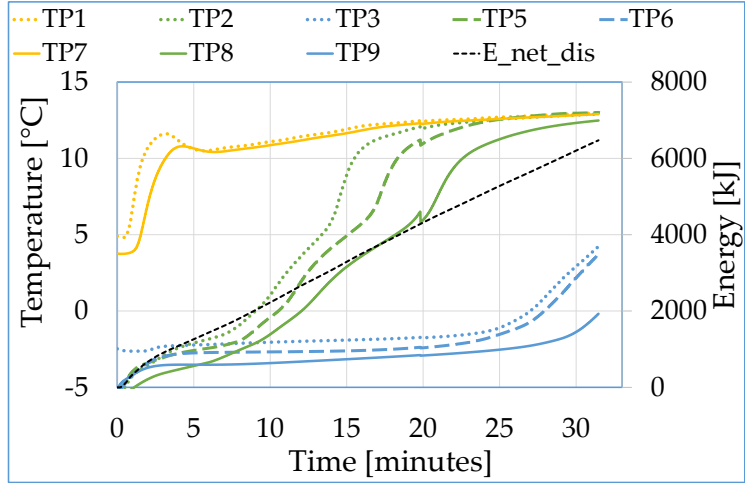

(b)

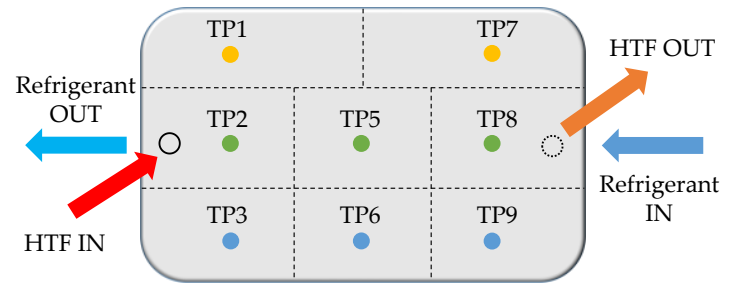

(d)

Figure 7. Results for the discharging process: (a) lab-scale temperature evolution and net energy recovered, (b) full-scale temperature evolution and net energy recovered, (c) location of lab-scale temperature sensors, and (d) location of full-scale temperature sensors.

In terms of energy, Figure 7a,b also show the net energy recovered from the TES modules during the discharging process. In the time interval corresponding to an increase in the average temperature from $-2{ }^{\circ} \mathrm{C}$ to $9{ }^{\circ} \mathrm{C}$, the net energy recovered from the modules was $769 \mathrm{~kJ}$ in $20.0 \mathrm{~min}$ for the lab-scale module and $6227 \mathrm{~kJ}$ in $30.7 \mathrm{~min}$ for the full-scale module. The equivalent average discharging power $\left(\overline{\dot{E}}_{d i s}\right)$ is $0.64 \mathrm{~kW}$ and $3.38 \mathrm{~kW}$ for the lab-scale and full-scale TES modules, respectively.

\subsection{Results of Calculated PIs}

Based on the results presented in the previous section, the different PIs defined in Section 2.5 were calculated as shown in Table 3 . The relative variation of the PIs values 
when going from lab-scale to full-scale were included in the table for a better evaluation of scaling up TES modules.

Table 3. PIs calculated for both modules for different normalizations.

\begin{tabular}{|c|c|c|c|c|c|c|}
\hline Performance Indicator (PI) & Normalization & Symbol & Units & Lab-Scale & Full-Scale & Variation \\
\hline PCM mass & mass & $m_{P C M @ m}$ & $\mathrm{~kg} \cdot \mathrm{kg}^{-1}$ & 0.11 & 0.19 & $73 \%$ \\
\hline \multirow[b]{2}{*}{ PCM volume } & volume & $V_{P C M @ V}$ & $\mathrm{~m}^{3} \cdot \mathrm{m}^{-3}$ & 0.04 & 0.11 & $178 \%$ \\
\hline & area & $V_{P C M @ A}$ & $\mathrm{~m}^{3} \cdot \mathrm{m}^{-2}$ & 0.014 & 0.015 & $4 \%$ \\
\hline \multirow{3}{*}{ Energy storage capacity } & mass & $E S C_{T E S @ m}$ & $\mathrm{~kJ} \cdot \mathrm{kg}^{-1}$ & 22.6 & 34.4 & $52 \%$ \\
\hline & volume & $E S C_{T E S @ V}$ & $\mathrm{MJ} \cdot \mathrm{m}^{-3}$ & 6.4 & 15.6 & $145 \%$ \\
\hline & area & $E S C_{T E S @ A}$ & $\mathrm{MJ} \cdot \mathrm{m}^{-2}$ & 2.27 & 2.09 & $-8 \%$ \\
\hline \multirow{3}{*}{ Charging power } & mass & $P_{\text {ch@m }}$ & $\mathrm{W} \cdot \mathrm{kg}^{-1}$ & 16.3 & 19.7 & $21 \%$ \\
\hline & volume & $P_{c h @ V}$ & $\mathrm{~kW} \cdot \mathrm{m}^{-3}$ & 4.6 & 9.0 & $94 \%$ \\
\hline & area & $P_{\text {ch@A }}$ & $\mathrm{kW} \cdot \mathrm{m}^{-2}$ & 1.6 & 1.2 & $-27 \%$ \\
\hline \multirow{3}{*}{ Discharging power } & mass & $P_{d i s @ m}$ & $\mathrm{~W} \cdot \mathrm{kg}^{-1}$ & 18.7 & 15.8 & $-16 \%$ \\
\hline & volume & $P_{d i s @ V}$ & $\mathrm{~kW} \cdot \mathrm{m}^{-3}$ & 5.3 & 7.2 & $36 \%$ \\
\hline & area & $P_{d i s @ A}$ & $\mathrm{~kW} \cdot \mathrm{m}^{-2}$ & 1.9 & 1.0 & $-49 \%$ \\
\hline Charging performance & - & $\varepsilon_{c h}$ & - & 0.97 & 0.81 & $-17 \%$ \\
\hline Discharging performance & - & $\varepsilon_{d i s}$ & - & 0.99 & 0.85 & $-15 \%$ \\
\hline Charging efficiency & - & $\eta_{c h}$ & - & 0.97 & 0.97 & $0 \%$ \\
\hline Discharging efficiency & - & $\eta_{\text {dis }}$ & - & 0.98 & 0.96 & $-1 \%$ \\
\hline Overall efficiency & - & $\eta_{\text {overall }}$ & - & 0.94 & 0.94 & $-1 \%$ \\
\hline
\end{tabular}

Starting with the structure PIs, one can see that the normalized PCM mass $\left(m_{P C M} @ m\right)$ is considerably higher $(73 \%)$ in the full-scale module compared to the lab-scale one. Likewise, the PCM volume normalized by volume $\left(V_{P C M @ V}\right)$ is $178 \%$ higher in the full-scale module compared to the lab-scale one. These results indicate a clear improvement of these two structures' PIs when scaling-up the module from lab-scale to full-scale. Nevertheless, when normalization by surface area is used (which is not affected by the amount of material in the modules), the PCM volume ( $\left.V_{P C M} @ A\right)$ has practically the same values at both scales.

Evaluating the next PI (energy storage capacity), the values corresponding to the full-scale module are significantly higher when mass and volume normalizations are used, with an increase as large as $145 \%$ in the case when normalization by volume is used. This is a direct consequence of the higher value of the share of PCM mass in the full-scale module compared to the lab-scale one, which leads to an increase in the total energy storage capacity due to the higher TES capacity of the PCM as compared with the other materials. However, it is interesting to note that, if surface area normalization is used, the full-scale module actually has a slightly lower ( $8 \%$ less) energy storage capacity.

Focusing on the average charging power normalized by mass $\left(P_{c h @ m}\right)$, an increase of $21 \%$ in the full-scale module is observed. When normalized by volume, the value of the average charging power $\left(P_{c h @ V}\right)$ of the full-scale module is almost twice the one of the lab-scale module. When normalization by surface area of heat transfer is used, results are completely different, and the average charging power $\left(P_{c h @ A}\right)$ is $27 \%$ lower in the full-scale module compared to the lab-scale one.

Regarding the average discharging power, it decreases by $16 \%$ in the full-scale module with respect to the lab-scale one when normalization by mass is used. However, when normalization by volume is used, the average discharging power increases by $36 \%$ in the full-scale module. When normalization by surface area is used, a reduction close to $50 \%$ in the average discharging power in the full-scale module is obtained compared to the lab-scale module.

The charging performance decreases from 0.97 in the lab-scale module to 0.81 in the full-scale one, which means a reduction of $17 \%$ in this PI as a result of the scaling up. A 
similar effect is observed in the discharging performance, which decreases from 0.99 in the lab-scale module to 0.85 in the full-scale one, which represents a reduction of $15 \%$.

Finally, a value of 0.97 was obtained for the charging efficiency in both lab-scale and full-scale cases. Similarly, the discharging efficiency in both cases had very similar values of around 0.97. As a result, an overall efficiency of 0.94 was obtained in both lab-scale and full-scale modules. No normalization was needed for both energy performance and all efficiency PIs because they are already normalized by definition.

\section{Discussion}

The previous section presented the main results obtained for the selected PIs calculated from experimental tests performed at both lab-scale and full-scale with a novel latent storage module that also acts as the evaporator of a vapor compression system. Different normalization methods were applied to some of the PIs to allow a meaningful comparison and a correct assessment of scaling up TES modules. Although the results obtained using the different normalization methods may be different, this does not mean that one is better than the other. It is just a consequence of the versatility of the novel module that allows it to be analyzed from different perspectives, both as a TES and HEX device.

When normalization by mass is used, the PCM mass ratio, the energy storage capacity, and the average charging power increase by $73 \%, 52 \%$, and $21 \%$, respectively, while the average discharging power decreases by $16 \%$, when going from lab-scale to full-scale. A similar trend is observed when normalization by volume is used, with a remarkable increase of the PCM volume ratio and the energy storage capacity by $178 \%$ and $145 \%$, respectively, and a considerable increase of the average charging and discharging power by $94 \%$ and $36 \%$, respectively. Therefore, when normalization methods typical for TES devices are used (i.e., by mass and volume of the TES device), most of the PIs are improved when going from lab-scale to full-scale.

When normalization by surface area of heat transfer is used, the PCM volume ratio and the energy storage capacity remain practically constant, while both the charging and discharging average power decrease by $27 \%$ and $49 \%$, respectively. Therefore, from a HEX perspective, the performance of the novel module gets worse, especially in discharge.

Regarding those PIs that do not require any normalization because they are already normalized by definition, it should be noted that both charging and discharging performance decrease by $17 \%$ and $15 \%$, respectively, when going from lab-scale to full-scale. However, the charging and the discharging efficiency, as well as the overall efficiency, remain constant after scaling up the TES module.

A qualitative summary of the variation of the PIs as a result of scaling up the TES module is shown in Table 4.

Table 4. Summary of the qualitative PIs variation due to scaling up. $\uparrow / \downarrow$ indicate a low effect that is increasing/decreasing with scaling up, $\uparrow \uparrow$ and $\downarrow \downarrow$ indicate a moderate effect that is increasing/decreasing with scaling up, and $\uparrow \uparrow \uparrow$ indicates a strong increasing effect with scaling up.

\begin{tabular}{|c|c|c|c|c|}
\hline \multirow{2}{*}{ PI } & \multicolumn{4}{|c|}{ Normalization Method } \\
\hline & Mass & Volume & Surface Area & None \\
\hline PCM mass & $\uparrow \uparrow$ & $x$ & $x$ & $x$ \\
\hline PCM volume & $x$ & $\uparrow \uparrow \uparrow$ & $\approx$ & $x$ \\
\hline Energy storage capacity & $\uparrow \uparrow$ & $\uparrow \uparrow \uparrow$ & $\approx$ & $\times$ \\
\hline Charging power & $\uparrow$ & $\uparrow \uparrow$ & $\downarrow$ & $\times$ \\
\hline Discharging power & $\downarrow$ & $\uparrow$ & $\downarrow \downarrow$ & $x$ \\
\hline Charging performance & $x$ & $x$ & $x$ & $\downarrow$ \\
\hline Discharging performance & $\times$ & $x$ & $x$ & $\downarrow$ \\
\hline Charging efficiency & $x$ & $x$ & $x$ & $\approx$ \\
\hline Discharging efficiency & $\times$ & $x$ & $x$ & $\approx$ \\
\hline Overall efficiency & $\times$ & $x$ & $x$ & $\approx$ \\
\hline
\end{tabular}


Therefore, in applications where the casing material and/or other materials contained in the TES device are dominant, as in this case (for instance, the mass ratio between aluminum and PCM is 5.5 in the lab-scale module and 3.7 in the full-scale module), the weight of the module might be an important aspect to be considered in the scaling up. Thus, normalization by mass is suitable for scaling up the TES device, which shows that most of the PIs considered in this study improve when going from lab-scale to full-scale. Likewise, in applications where the TES device has a high share of insulating material, normalization by volume could be the most significant. In the case of the module considered in this study, $87 \%$ of the volume of the lab-scale module and $75 \%$ in the full-scale module corresponds to the insulation material. As a consequence, when normalization by volume is used, all PIs normalized by volume improve when scaling up the TES module.

When normalization by surface area of heat transfer is used, the amount of materials, such as the aluminum and the insulation, does not affect the results. This is so because normalization by surface area only takes into account the characteristics related to the configuration of the part of the TES module where heat transfer takes place. For instance, the ratio between PCM volume and surface area of heat transfer is practically constant $\left(14 \mathrm{~L} \cdot \mathrm{m}^{-2}\right.$ and $15 \mathrm{~L} \cdot \mathrm{m}^{-2}$ in the lab-scale and full-scale cases, respectively), which explains why the energy storage capacity remains practically constant when going from lab-scale to full-scale. Therefore, in applications where there are no weight or space limitations, and the analysis relies on characteristics related to the heat transfer region of the module, this normalization method could be more adequate to study the scaling up. Such an analysis allows design improvement for different applications. Indeed, the latent heat storage system investigated here was studied for different applications, such as the replacement of a standard evaporator in a heat pump for residential buildings [25] and the use for domestic hot water (DHW) production directly from a heat pump cycle in colder climates [12]. Since different applications have different constraints, starting from the analysis here presented, different applications can be targeted and optimized. For instance, for DHW production higher power output is needed, whereas for cold generation applications a higher capacity is desirable.

\section{Conclusions}

Two novel latent TES modules of different sizes were experimentally tested to compare their performance and identify some key aspects to be considered when scaling up the modules from small-scale to large-scale sizes. The small-sized TES module is a lab-scale prototype that was manufactured and tested to demonstrate the feasibility of the concept and to determine possible improvements in the design of the module. The large-sized TES module is a real-scale prototype that was first tested in a laboratory environment prior to its integration as latent storage component of a real-scale demonstration system developed within the H2020 HYBUILD project.

The comparison between the two TES modules was performed through different performance indicators related to the behavior of the modules in both charge and discharge modes. To achieve a thorough comparison between the two-size modules, which should allow for a better assessment of the scaling up the TES module, different normalization methods were used when necessary.

The following main conclusions can be drawn as a result of the scaling up from lab-scale to full-scale:

- Different normalization methods can be applied to some of the PIs, depending on the focus of the study and the intended application, which may even lead to discrepant results. When a mass normalization method is used, an improvement in the PCM mass, energy storage capacity, and average charging power is observed, while the average discharging power decreases.

- When a volume normalization method is used, PCM volume, energy storage capacity, and average charging and discharging power increase, especially PCM volume, and energy storage capacity. 
- When normalization by surface area of heat transfer is used, no significant changes are obtained in terms of PCM volume and TES capacity of the modules. However, both average charging and discharging power decrease.

- A slight reduction in the energy performance in charge and discharge is observed.

- No significant influence of the scaling up is observed on the charging, discharging, and overall efficiencies.

Therefore, the results obtained at lab-scale for the charging, discharging, and overall efficiencies can be used to extrapolate the behavior of the TES module when it is scaled up to the real-scale application. However, a reduction around 15\% in the TES module performance in both charge and discharge should be applied when going from lab-scale to full-scale. Special care should be taken when using the average charging and discharging powers, energy storage capacity, and PCM ratio for scaling up the TES module, because they behave differently depending on the normalization method used.

Further studies could consist in the application of the methodological approach applied in this study for scaling up other TES modules of different type and geometries.

Author Contributions: Conceptualization, L.F.C., G.Z., A.F. and V.P.; methodology, A.F., V.P., L.F.C., G.Z., B.D.M., D.V. and E.B.; formal analysis, G.Z. and B.D.M.; investigation, G.Z., D.V., B.D.M. and V.P.; resources, A.F., B.N., A.S. and L.F.C.; writing-original draft preparation, G.Z., V.P. and B.D.M.; writing-review and editing, E.B., D.V., A.F., B.N. and L.F.C.; visualization, B.D.M., G.Z. and V.P.; supervision, L.F.C. and A.F.; project administration, L.F.C. and A.F.; funding acquisition, L.F.C., A.F. and A.S. All authors have read and agreed to the published version of the manuscript.

Funding: This project has received funding from the European Union's Horizon 2020 research and innovation programme under grant agreement No. 768824 (HYBUILD). This work was partially funded by the Ministerio de Ciencia, Innovación y Universidades de España (RTI2018-093849-B-C31MCIU/AEI/FEDER, UE) and by the Ministerio de Ciencia, Innovación y Universidades-Agencia Estatal de Investigación (AEI) (RED2018-102431-T). This work is partially supported by ICREA under the ICREA Academia programme.

Institutional Review Board Statement: Not applicable.

Informed Consent Statement: Not applicable.

Data Availability Statement: Data is available upon request to the correspondence author.

Acknowledgments: The authors would like to thank the Catalan Government for the quality accreditation given to their research group (2017 SGR 1537). GREiA is certified agent TECNIO in the category of technology developers from the Government of Catalonia. Boniface Dominick Mselle would like to thank Programa Santander Predoc UdL for his research fellowship.

Conflicts of Interest: The authors declare no conflict of interest. The funders had no role in the design of the study; in the collection, analyses, or interpretation of data; in the writing of the manuscript, or in the decision to publish the results.

\section{References}

1. European Commission. EU 2030 Climate E Energy Framework; European Commission: Brussels, Belgium, 2014.

2. European Commission. Strategic Energy Technology Plan Implementation Plan; European Commission: Brussels, Belgium, 2018.

3. Tejero-González, A.; Andrés-Chicote, M.; García-Ibáñez, P.; Velasco-Gómez, E.; Rey-Martínez, F.J. Assessing the applicability of passive cooling and heating techniques through climate factors: An overview. Renew. Sustain. Energy Rev. 2016, 65, 727-742. [CrossRef]

4. Gullbrekken, L.; Grynning, S.; Gaarder, J.; Gullbrekken, L.; Grynning, S.; Gaarder, J.E. Thermal performance of insulated constructions-Experimental studies. Buildings 2019, 9, 49. [CrossRef]

5. Fernandez-Antolin, M.-M.; Del Río, J.M.; Costanzo, V.; Nocera, F.; Gonzalez-Lezcano, R.-A. Passive design strategies for residential buildings in different spanish climate zones. Sustainability 2019, 11, 4816. [CrossRef]

6. Palomba, V.; Borri, E.; Charalampidis, A.; Frazzica, A.; Cabeza, L.F.; Karellas, S. Implementation of a solar-biomass system for multi-family houses: Towards 100\% renewable energy utilization. Renew. Energy 2020, 166, 190-209. [CrossRef]

7. Palomba, V.; Borri, E.; Charalampidis, A.; Frazzica, A.; Karellas, S.; Cabeza, L.F. An innovative solar-biomass energy system to increase the share of renewables in office buildings. Energies 2021, 14, 914. [CrossRef]

8. Stalinski, D.; Duquette, J. Development of a simplified method for optimally sizing hot water storage tanks subject to short-term intermittent charge/discharge cycles. J. Energy Storage 2021, 37, 102463. [CrossRef] 
9. Singh, R.V.P.; Singh, J.; Mathur, J.; Bhandari, M. Calibrated simulation study for efficient sizing and operating strategies for the thermal storage integrated air conditioning system. Int. J. Sustain. Energy 2021, 40, 389-411. [CrossRef]

10. Pandey, B.; Banerjee, R.; Sharma, A. Coupled EnergyPlus and CFD analysis of PCM for thermal management of buildings. Energy Build. 2021, 231, 110598. [CrossRef]

11. Barone, G.; Buonomano, A.; Forzano, C.; Palombo, A. A novel dynamic simulation model for the thermo-economic analysis and optimisation of district heating systems. Energy Convers. Manag. 2020, 220, 113052. [CrossRef]

12. Emhofer, J.; Marx, K.; Barz, T.; Hochwallner, F.; Cabeza, L.F.; Zsembinszki, G.; Strehlow, A.; Nitsch, B.; Wiesflecker, M.; Pink, W. Techno-economic analysis of a heat pump cycle including a three-media refrigerant/phase change material/water heat exchanger in the hot superheated section for efficient domestic hot water generation. Appl. Sci. 2020, 10, 7873. [CrossRef]

13. Arabkoohsar, A.; Behzadi, A.; Alsagri, A.S. Techno-economic analysis and multi-objective optimization of a novel solar-based building energy system; An effort to reach the true meaning of zero-energy buildings. Energy Convers. Manag. 2021, 232, 113858. [CrossRef]

14. Barone, G.; Buonomano, A.; Forzano, C.; Palombo, A.; Panagopoulos, O. Experimentation, modelling and applications of a novel low-cost air-based photovoltaic thermal collector prototype. Energy Convers. Manag. 2019, 195, 1079-1097. [CrossRef]

15. Hulteberg, C.; Leveau, A. Scaling up a gas-phase process for converting glycerol to propane. Catalysts 2020, 10, 1007. [CrossRef]

16. Della Torre, A.; Montenegro, G.; Onorati, A.; Khadilkar, S.; Icarelli, R. Multi-scale CFD modeling of plate heat exchangers including offset-strip fins and dimple-type turbulators for automotive applications. Energies 2019, 12, 2965. [CrossRef]

17. Prieto, C.; Osuna, R.; Fernández, A.I.; Cabeza, L.F. Molten salt facilities, lessons learnt at pilot plant scale to guarantee commercial plants; heat losses evaluation and correction. Renew. Energy 2016, 94, 175-185. [CrossRef]

18. Touzo, A.; Olives, R.; Dejean, G.; Pham Minh, D.; El Hafi, M.; Hoffmann, J.F.; Py, X. Experimental and numerical analysis of a packed-bed thermal energy storage system designed to recover high temperature waste heat: An industrial scale up. J. Energy Storage 2020, 32, 101894. [CrossRef]

19. Patil, R.S.; Pandey, M.; Mahanta, P. Parametric studies and effect of scale-up on wall-to-bed heat transfer characteristics of circulating fluidized bed risers. Exp. Therm. Fluid Sci. 2011, 35, 485-494. [CrossRef]

20. Godoy, V.A.; Zuquette, L.V.; Gómez-Hernández, J.J. Scale effect on hydraulic conductivity and solute transport: Small and large-scale laboratory experiments and field experiments. Eng. Geol. 2018, 243, 196-205. [CrossRef]

21. Wang, X.Y.; Spearpoint, M.J.; Fleischmann, C.M. Comparison of results from large-scale and small-scale tunnel experiments. Fire Saf. J. 2018, 95, 135-144. [CrossRef]

22. Sun, X.; Hu, L.; Zhang, X.; Yang, Y.; Ren, F.; Fang, X.; Wang, K.; Lu, H. Temperature evolution and external flame height through the opening of fire compartment: Scale effect on heat/mass transfer and revisited models. Int. J. Therm. Sci. 2021, 164, 106849. [CrossRef]

23. Frankovič, A.; Ducman, V.; Dolenec, S.; Panizza, M.; Tamburini, S.; Natali, M.; Pappa, M.; Tsoutis, C.; Bernardi, A. Up-scaling and performance assessment of façade panels produced from construction and demolition waste using alkali activation technology. Constr. Build. Mater. 2020, 262, 120475. [CrossRef]

24. HYBUILD. Available online: http:/ / www.hybuild.eu/ (accessed on 4 December 2020).

25. Palomba, V.; Bonanno, A.; Brunaccini, G.; Aloisio, D.; Sergi, F.; Dino, G.E.; Varvaggiannis, E.; Karellas, S.; Nitsch, B.; Strehlow, A.; et al. Hybrid cascade heat pump and thermal-electric energy storage system for residential buildings: Experimental testing and performance analysis. Energies 2021, 14, 2580. [CrossRef]

26. Mselle, B.D.; Vérez, D.; Zsembinszki, G.; Borri, E.; Cabeza, L.F. Performance study of direct integration of phase change material into an innovative evaporator of a simple vapour compression system. Appl. Sci. 2020, 10, 4649. [CrossRef]

27. Brancato, V.; Gordeeva, L.G.; Sapienza, A.; Palomba, V.; Vasta, S.; Grekova, A.D.; Frazzica, A.; Aristov, Y.I. Experimental characterization of the $\mathrm{LiCl} /$ vermiculite composite for sorption heat storage applications. Int. J. Refrig. 2018, 105, 92-100. [CrossRef]

28. Rubitherm RT-PCM. Available online: https://www.rubitherm.eu/en/index.php/productcategory/organische-pcm-rt (accessed on 2 October 2019).

29. Mselle, B.D.; Zsembinszki, G.; Vérez, D.; Borri, E.; Cabeza, L.F. A detailed energy analysis of a novel evaporator with latent thermal energy storage ability. Appl. Therm. Eng. 2021, in press.

30. Carvill, J. Thermodynamics and heat transfer. Mech. Eng. Data Handb. 1993, 102-145. [CrossRef]

31. IT, R. Rockwool Data Sheet. Available online: https://www.rockwool.com/north-america/resources-and-tools/documentation/ (accessed on 2 October 2019).

32. ISOVER Saint-Gobain Data Sheet TECH Wired Mat MT 3.1. Available online: https://www.isover.es/productos/tech-wiredmat-mt-31 (accessed on 2 October 2019).

33. Palomba, V.; Frazzica, A. A fast-reduced model for an innovative latent thermal energy storage for direct integration in heat pumps. Appl. Sci. 2021, 11, 8972. [CrossRef]

34. Palomba, V.; Frazzica, A.; Gasia, J.; Cabeza, L.F. Experimental characterization of latent thermal energy storage systems. In Recent Advancements in Materials and Systems for Thermal Energy Storage-An Introduction to Experimental Characterization Methods; Frazzica, A., Cabeza, L.F., Eds.; Springer: Berlin/Heidelberg, Germany, 2019; pp. 173-200, ISBN 978-3-319-96640-3.

35. Palomba, V.; Gasia, J.; Romaní, J.; Frazzica, A.; Cabeza, L.F. Definition of performance indicators for thermal energy storage. In Recent Advancements in Materials and Systems for Thermal Energy Storage-An Introduction to Experimental Characterization Methods; Frazzica, A., Cabeza, L.F., Eds.; Springer: Berlin/Heidelberg, Germany, 2019; pp. 227-242, ISBN 978-3-319-96640-3. 